\title{
Investigation of blood microcirculation parameters in patients with rheumatic diseases by videocapillaroscopy and laser Doppler flowmetry during cold pressor test
}

Stavtsev, Dmitry, Volkov, Mikhail, Margaryants, Nikita , Potemkin, Andrey, Dremin, Viktor, et al.

Dmitry D. Stavtsev, Mikhail V. Volkov, Nikita B. Margaryants, Andrey V. Potemkin, Viktor V. Dremin, Igor O. Kozlov, Irina N. Makovik, Evgeny A. Zherebtsov, Andrey V. Dunaev, "Investigation of blood microcirculation parameters in patients with rheumatic diseases by videocapillaroscopy and laser Doppler flowmetry during cold pressor test," Proc. SPIE 11065, Saratov Fall Meeting 2018: Optical and Nano-Technologies for Biology and Medicine, 110650T (3 June 2019); doi: 10.1117/12.2523190 


\title{
Investigation of blood microcirculation parameters in patients with rheumatic diseases by videocapillaroscopy and laser Doppler flowmetry during cold pressor test
}

\author{
Dmitry D. Stavtsev*a , Mikhail V. Volkov ${ }^{\mathrm{b}}$, Nikita B. Margaryants ${ }^{\mathrm{b}}$, Andrey V. Potemkin ${ }^{\mathrm{b}}$, \\ Viktor V. Dremin ${ }^{\mathrm{a}}$, Igor O Kozlov ${ }^{\mathrm{a}}$, Irina N. Makovik ${ }^{\mathrm{a}}$, Evgeny A. Zherebtsov ${ }^{\mathrm{c}}$, Andrey V. Dunaev ${ }^{\mathrm{a}}$ \\ ${ }^{a}$ Research and Development Center of Biomedical Photonics, Orel State University \\ named after I.S. Turgenev, 302020, Orel, Russia; \\ bITMO University, 197101, Saint-Petersburg, Russia; \\ ${ }^{\mathrm{c} O P E M}$, University of Oulu, 90014, Oulu, Finland
}

\begin{abstract}
Videocapillaroscopy (VCS) and laser Doppler flowmetry (LDF) are non-invasive methods for evaluating microcirculation parameters. The VCS method is based on a high-speed video recording of capillaries in the nailfold. The recorded video frames are processed using a specialized algorithm to determine the red blood cells velocity. The LDF technique is based on the analysis of the Doppler shift of back-scattered laser radiation from moving red blood cells. In this work, simultaneous measurements of VCS and LDF have been performed in healthy volunteers and rheumatic patient. The study was conducted using a cold pressor test. Changes were recorded in response to cold exposure in rheumatic diseases.
\end{abstract}

Keywords: videocapillaroscopy, laser Doppler flowmetry, velocity of capillary blood flow, microcirculation, rheumatic diseases, cold pressor test

\section{INTRODUCTION}

At the moment microcirculation parameters can be non-invasively investigated by videocapillaroscopy (VCS) method and laser Doppler flowmetry (LDF). The VCS method is based on a high-speed video recording of nailfold capillaries at high magnification. After mathematical processing of the obtained sequences of frames, the red blood cells velocity in a single capillary can be determined ${ }^{1}$. Also, this method allows evaluating the morphology of a capillary network, which also provides significant information about the state of the microcirculatory system. Currently, the LDF method is well studied and widely used in practice. This technology is based on probing the tissue with low-intensity laser radiation and recording the back-scattered radiation. Probing radiation is scattered by moving red blood cells, which causes a Doppler shift analyzed to determine the rate of microcirculation characterizing the microhemodynamics in the tissue. The perfusion is measured in dimensionless perfusion units and depends on the velocity and concentration of red blood cells in the diagnostic volume. Unlike LDF, the VCS method allows to determine the red blood cells velocity in a single capillary, as well as to visually and quantitatively assess the morphology of the capillary network. The described differences in the field of research and diagnostic information between the two methods make their combined use promising. At the same time, a frequency analysis of blood flow fluctuations makes it possible to identify blood flow rhythms that characterize various mechanisms of regulation of peripheral blood flow.

Rheumatic diseases are associated with pathological processes in the connective tissue and manifested in architectural disorganization of capillaries, changes in microhemodynamics and violations of regulation mechanisms.

This work aimed to investigate the relationship between VCS and LDF methods in the study of microcirculation disorders in rheumatic diseases. In particular, the purpose was to assess changes in the morphology of the capillary network, perfusion and the red blood cells velocity in patients with rheumatic diseases compared to healthy volunteers.

To assess the functional state of the microcirculatory bed and reserve capacity of the blood flow cold pressor test was used $^{2}$.

*stavtsev.dmitry@gmail.com; phone+7953 611-8023; http://www.bmecenter.ru/en 


\section{MATERIAL AND METHODS}

An experimental setup was designed for videocapillaroscopy, the optical system of which was based on Mitutoyo M Plan APO 5X objective and optomechanical components of Thorlabs. To illuminate the field of view, a side LED illumination at wavelength of $560 \mathrm{~nm}$ is used to increase the contrast of observed images as it corresponds with high absorption of light by the blood. The data was captured using CMOS camera IDS UI-3060-C-HQ, providing resolution of $800 \times 800$ pixels at a frame rate of $150 \mathrm{fps}$. The optical system is constructed on an adjustable tripod, providing focusing on the field under study. The camera is connected to PC through USB 3.0. Data is recorded on the SSD using the specially developed software. Processing of the obtained video fragments including stabilization procedures ${ }^{3}$, contrasting, compensation of the image background and determination of the capillary blood flow rate are performed using specially developed software ${ }^{1}$.

To measure the perfusion, multifunctional laser non-invasive diagnostic system "LAKK-M" (SPE "LAZMA" Ltd, Russia) was used. The wavelength of the laser radiation in the LDF measurement channel is $1064 \mathrm{~nm}$. During the study, the blood perfusion records have been registered using the system, and the wavelet analysis of the signals has been performed by the software of SPE "LAZMA".

In previous work, the measurements of the microhemodynamic parameters were carried out by the VSC and LDF methods in different fingers of one hand ${ }^{4}$. In this work, the optical fiber of the LDF channel was placed on the finger-pad of the distal phalanx of the same finger where in the nail bed the VCS video signal was recorded.

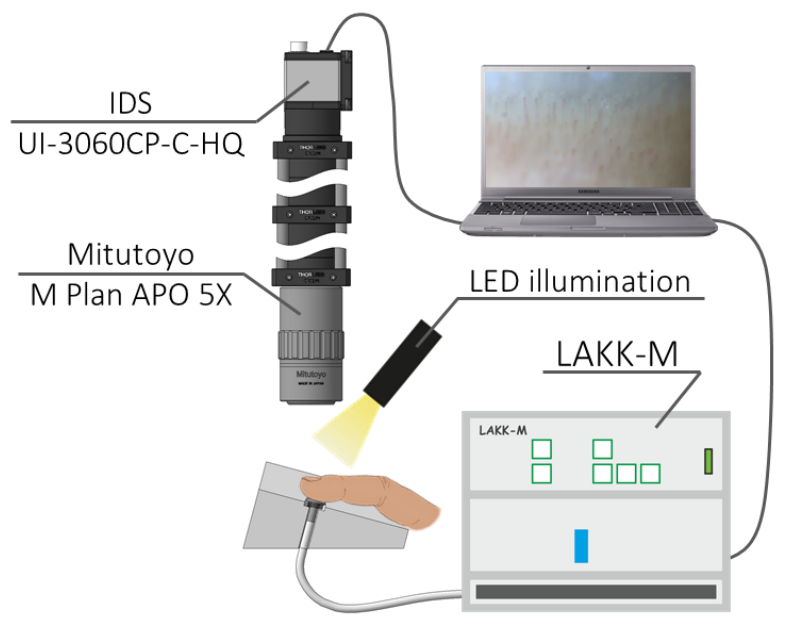

Figure 1. Scheme of the experimental setup.

In this study, we used a cold pressor test (CPT) with the dipping hands in the water at a temperature of $15{ }^{\circ} \mathrm{C} .{ }^{5} \mathrm{The}$ duration of the cooling was 5 minutes $^{6}$. The experimental protocol (Fig 2) involves three measurement series (BT1, BT2, BT3). BT1 and BT2 are recorded before and immediately after the CPT respectively. The BT3 measurement is performed 20 minutes after the cooling in water. The time span has been chosen as the recovery of the capillary microcirculation after the cooling with the temperature of $15^{\circ} \mathrm{C}$ takes $15-20$ minutes $^{7}$

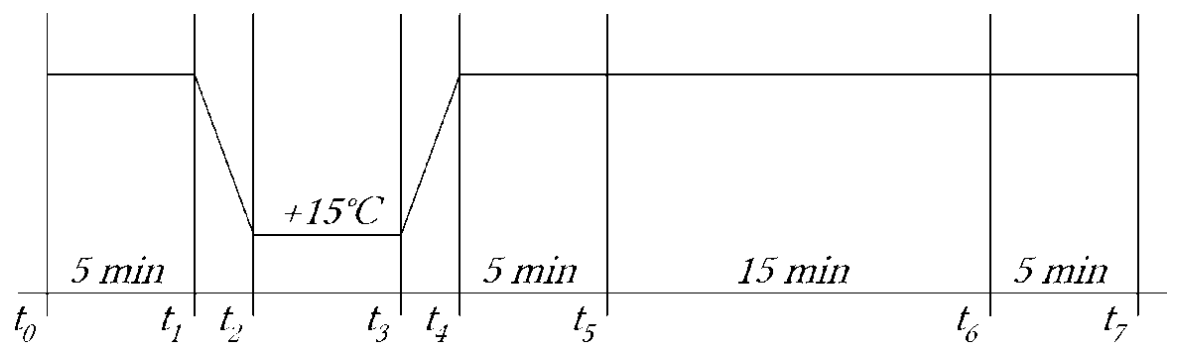

Figure 2. Scheme of the study.

Studies were conducted on the fourth finger of the right hand. This finger was chosen because the fourth and fifth fingers are the least involved ones in work, less prone to injury and have more transparent skin ${ }^{8}$. 


\section{EXPERIMENTAL RESULTS AND DISCUSSION}

During a study by VCS on patients with microcirculatory disorders, it is necessary to pay attention to the accompanying changes in the morphology of the capillary link of the peripheral circulatory system. Fig. 3 shows images of nailfold capillaries of the fingers of a healthy volunteer and a patient with rheumatic disorders.

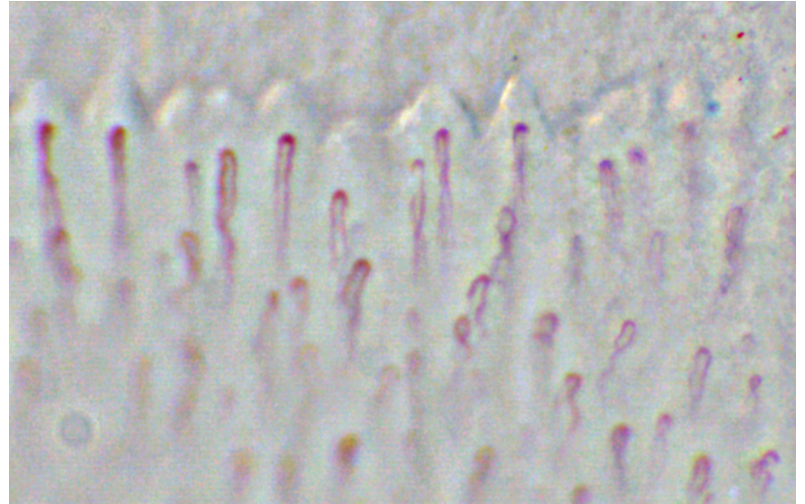

(a)

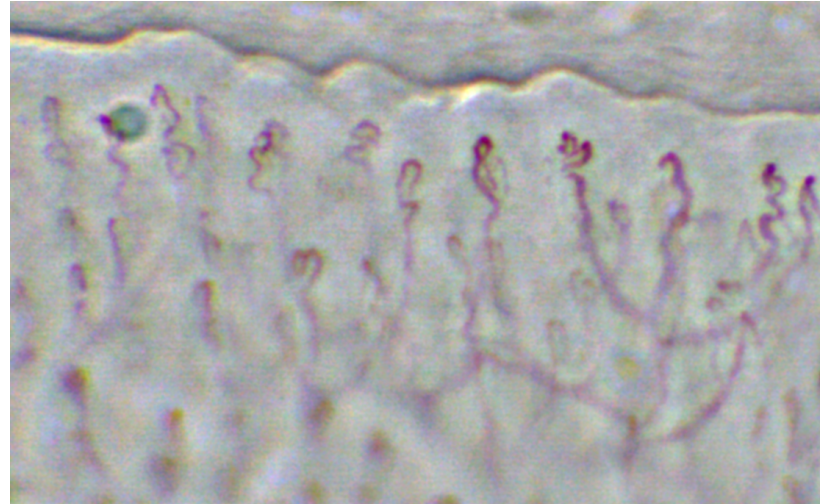

(b)

Figure 3. Image of the capillary bed of a healthy volunteer (a) and a patient with rheumatic disease (b).

The presented images (Fig. 3) clearly show that the capillaries of the healthy person are shaped like a hair pin or like the letter "U" upside-down. In the patient with rheumatic disease distortions of capillaries with more visible subpapillary venous plexus in comparison with healthy volunteers were revealed".

Fig. 4 and 5 show graphs of changes in the red blood cells velocity and LDF-signals obtained during each stage of the measurements.

a)
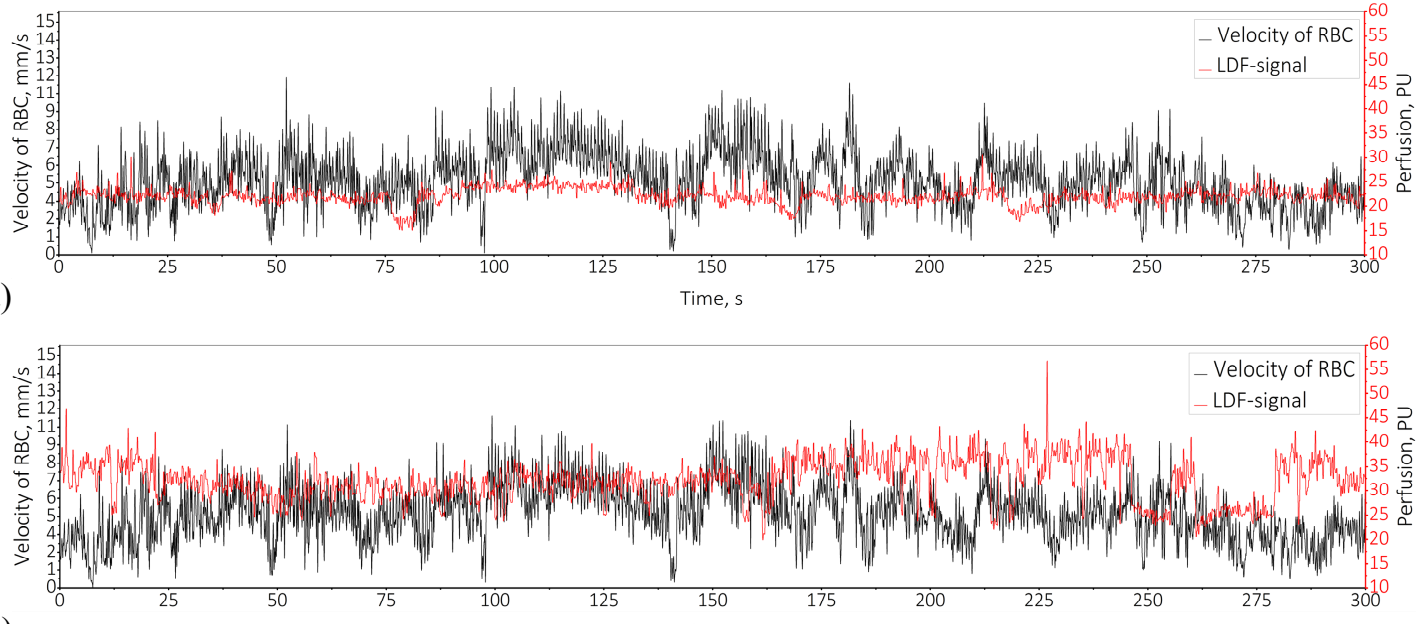

b)

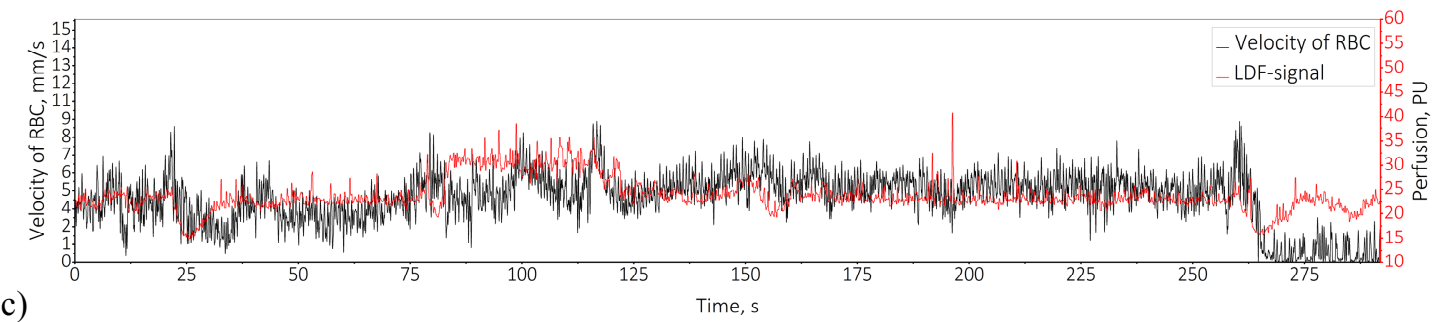

Figure 4. Graphs of changes in the red blood cells velocity and LDF-signals of the healthy volunteer, before the CPT (a), immediately after the CPT (b) and 20 minutes after the CPT (c). 


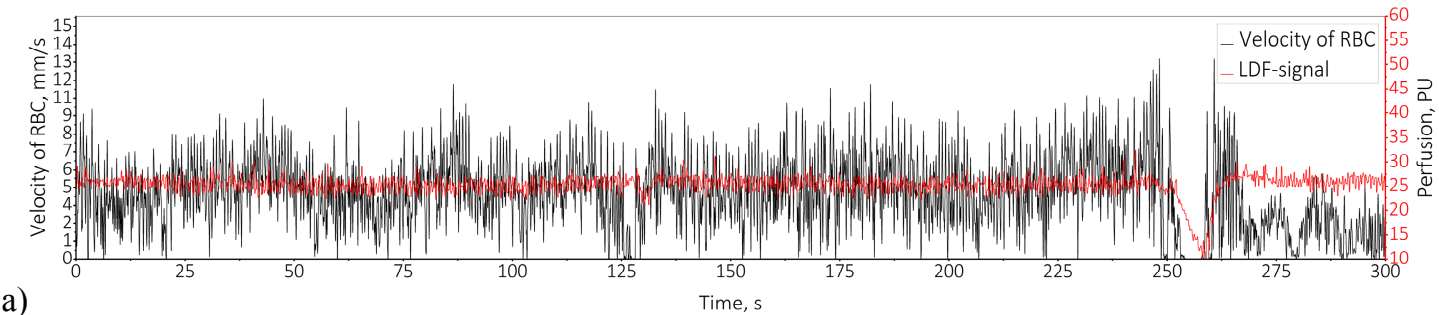

a)

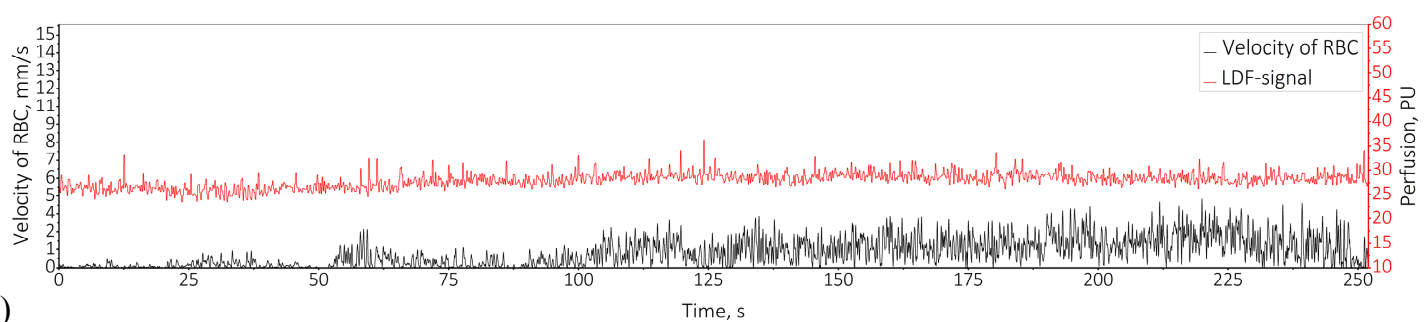

b)

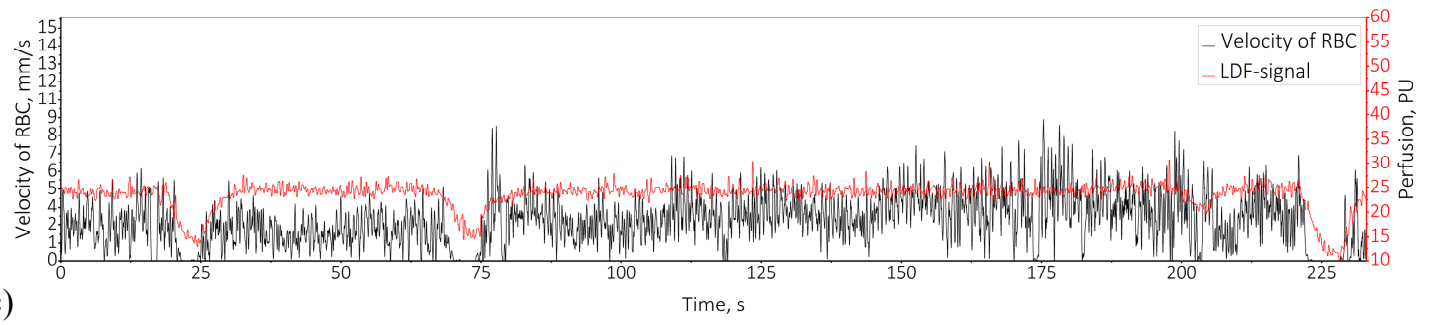

Figure 5. Registered changes in the red blood cells velocity and LDF-signals of the patient with the rheumatic disease, before the CPT (a), immediately after CPT (b) and 20 min after the holding of the CPT (c).

The contribution of different parts of the microcirculatory bed to the total microcirculation is estimated by the bypass index and the level of nutritive blood flow ${ }^{10}$.

The bypass index is defined as:

$$
\begin{aligned}
& B I=B I 1+B I 2 \\
& B I 1=1+A_{n} / A_{m} \\
& B I 2=A_{\text {pass }} / A_{m}
\end{aligned}
$$

$A_{n}, A_{m}$ - the oscillation amplitudes of blood flow in neurogenic and myogenic range;

$A_{p a s} s$ - the maximum oscillation amplitude of blood flow in the cardiac or respiratory range. BI2 is taken into account in the calculation of bypass index if $B I 2 \geq 1$.

$I_{\text {mnutr }}$ - the proportion of nutritive blood flow in the general microcirculation, $P U$ :

$$
I_{\text {mnutr }}=I_{m} / B I
$$

$I_{m}$ - the index of blood microcirculation (perfusion), $P U$;

An example of the measured and calculated parameters of microcirculation in a healthy volunteer and a patient with the rheumatic disease are presented in tables 1 and 2 , respectively. 
Table 1. Microcirculation parameters of microcirculation in a healthy volunteer.

\begin{tabular}{|l|l|l|l|l|l|l|}
\hline \multirow{2}{*}{$\begin{array}{c}\text { Base } \\
\text { test }\end{array}$} & \multicolumn{6}{c|}{ Parameter } \\
\cline { 2 - 7 } & $I_{m}, P U$ & $\sigma\left(I_{m}\right), P U$ & $B I, A U$ & $I_{\text {mnutr }}, P U$ & $V, m m / s$ & $\sigma(V), \mathrm{mm} / \mathrm{s}$ \\
\hline$B T 1$ & 22.0 & 1.7 & 1.3 & 16.7 & 4.8 & 1.7 \\
\hline$B T 2$ & 32.1 & 4.3 & 2.4 & 13.0 & 4.8 & 1.7 \\
\hline$B T 3$ & 23.8 & 3.3 & 1.8 & 13.1 & 4.2 & 1.6 \\
\hline
\end{tabular}

Table 2. Microcirculation parameters in a patient with rheumatic disease.

\begin{tabular}{|l|l|l|l|l|l|l|}
\hline \multirow{2}{*}{$\begin{array}{c}\text { Base } \\
\text { test }\end{array}$} & \multicolumn{6}{c|}{ Parameter } \\
\cline { 2 - 8 } & $I_{m}, P U$ & $\sigma\left(I_{m}\right), P U$ & $B I, A U$ & $I_{\text {mnutr }}, P U$ & $V, \mathrm{~mm} / \mathrm{s}$ & $\sigma(\mathrm{V}), \mathrm{mm} / \mathrm{s}$ \\
\hline$B T 1$ & 25.0 & 2.6 & 3.8 & 6.5 & 4.2 & 2.3 \\
\hline$B T 2$ & 27.1 & 3.0 & 2.3 & 11.4 & 0.8 & 0.8 \\
\hline$B T 3$ & 23.3 & 2.7 & 2.0 & 11.6 & 2.2 & 1.6 \\
\hline
\end{tabular}

In the healthy volunteer, there is an increase in the perfusion by $10 \mathrm{PU}$, accompanied by a decrease in nutritive blood flow $\left(\mathrm{I}_{\text {mnutrl }}=16,7 \mathrm{PU}, \mathrm{I}_{\text {mnutr2 }}=13,0 \mathrm{PU}, \mathrm{I}_{\text {mnutr } 3}=13.1 \mathrm{PU}\right)$ and increased shunt blood flow $(\mathrm{BI}=11,3 \mathrm{AU}, \mathrm{BI}=2,4 \mathrm{AU}$, $\mathrm{BI} 3=1,8 \mathrm{AU})$ after CPT. In this case, the average red blood cells velocity does not change. In the patient with the rheumatic disease, the change in the perfusion is less significant (2 PU), in this case, there is a decrease in bypass index $(\mathrm{BI} 1=3,8 \mathrm{AU}, \mathrm{BI}=2,3 \mathrm{AU}, \mathrm{BI}=2,0 \mathrm{AU})$ and an increase in nutritive blood flow $\left(\mathrm{I}_{\mathrm{mnutr} 1}=6,5 \mathrm{PU}, \mathrm{I}_{\mathrm{mnutr} 2}=11,4 \mathrm{PU}\right.$, $\left.\mathrm{I}_{\mathrm{mnutr3}}=11,1 \mathrm{PU}\right)$. In addition to an increase in the perfusion, there is a decrease in the red blood cells velocity after CPT and a slower rate of its recovery $(\mathrm{V}=4,2 \mathrm{~mm} / \mathrm{s}, \mathrm{V}=0,8 \mathrm{~mm} / \mathrm{s}, \mathrm{V}=2,2 \mathrm{~mm} / \mathrm{s})$.

\section{CONCLUSION}

The obtained results show the possibility of combined use of VCS and LDF techniques for obtaining more comprehensive diagnostic information. The changes in the velocity of red blood cells after applying a cold pressor test were registered. The difference in blood perfusion and RBC velocity in one capillary recorded by the methods of VCS and LDF were revealed in the patient with rheumatic disease. After the CPT, in patients had been observed a significant decrease in the red blood cells velocity with an increase in perfusion and nutritive blood flow. The obtained different behavior of the signals requires additional studies to explain the revealed effects. The results of the study can underlie further research with a more significant number of volunteers.

\section{ACKNOWLEDGMENTS}

The research was supported by the grant of the RFBR-r_a (project 17-41-590560) in respect of the design and assembling of the experimental setup; by the grant of the President of the Russian Federation for state support of young Russian scientists № MK-3400.2018.8 in respect of conducting of the experiments; by Ministry of Science and Higher Education of the Russian Federation (Project No. 8.2501.2017/4.6) in respect of the design of the method and algorithm of VCS data processing and by the Russian Science Foundation (the research project 18-79-00237) in respect of LDF data processing and analysis, formulation of conclusions.

\section{REFERENCES}

[1] Gurov, I., Volkov, M., Margaryants, N., Pimenov, A. and Potemkin, A., "High-speed video capillaroscopy method for imaging and evaluation of moving red blood cells," Opt. Lasers Eng. 104, 244-251 (2018). 
[2] Makovik, I. N., Dunaev, A. V., Dremin, V. V., Krupatkin, A. I., Sidorov, V. V., Khakhicheva, L. S., Muradyan, V. F., Pilipenko, O. V., Rafailov, I. E. and Litvinova, K. S., "Detection of angiospastic disorders in the microcirculatory bed using laser diagnostics technologies," J. Innov. Opt. Health Sci. 11(1) (2018).

[3] Karimov, K. A. and Volkov, M. V., "The phase correlation algorithm for stabilization of capillary blood flow video frames,” Proc. SPIE - Int. Soc. Opt. Eng. 9528, 952810-952819 (2015).

[4] Volkov, M. V, Kostrova, D. A., Margaryants, N. B., Gurov, I. P., Erofeev, N. P., Dremin, V. V, Zharkikh, E. V, Zherebtsov, E. A., Kozlov, I. O. and Dunaev, A. V., "Evaluation of blood microcirculation parameters by combined use of laser Doppler flowmetry and videocapillaroscopy methods," Proc. SPIE - Int. Soc. Opt. Eng. 10336, 1033606-1033607 (2017).

[5] Harada, N., "Cold-stress tests involving finger skin temperature measurement for evaluation of vascular disorders in hand-arm vibration syndrome: review of the literature.," Int. Arch. Occup. Environ. Health 75(1-2), 14-19 (2002).

[6] Ammer, K., "Cold challenge to provoke a vasospastic reaction in fingers determined by temperature measurements: A systematic review," Thermol. Int. 19(4), 109-118 (2009).

[7] Bartelink, M. L., Wollersheim, H., Leesmans, E., De Boo, T. and Thien, T., "A standardized finger cooling test for Raynaud's phenomenon: Diagnostic value and sex differences," Eur. Heart J. 14(5), 614-622 (1993).

[8] Cutolo, M., Grassi, W. and Matucci Cerinic, M., "Raynaud's phenomenon and the role of capillaroscopy," Arthritis Rheum. 48(11), 3023-3030 (2003).

[9] Tavakol, M. E., Fatemi, A., Karbalaie, A., Emrani, Z. and Erlandsson, B. E., "Nailfold Capillaroscopy in Rheumatic Diseases: Which Parameters Should Be Evaluated?," Biomed Res. Int. 2015 (2015).

[10] Dunaev, A. V., Sidorov, V. V., Krupatkin, A. I., Rafailov, I. E., Palmer, S. G., Stewart, N. A., Sokolovski, S. G. and Rafailov, E. U., "Investigating tissue respiration and skin microhaemocirculation under adaptive changes and the synchronization of blood flow and oxygen saturation rhythms," Physiol. Meas. 35(4), 607-621 (2014). 